\title{
Improvement of maternal Aboriginality in NSW birth data
}

\author{
Fenglian $\mathrm{Xu}^{1}$, Elizabeth A Sullivan ${ }^{1}$, Richard C Madden², Deborah Black ${ }^{2}$ and Lisa R Jackson Pulver ${ }^{3 *}$
}

\begin{abstract}
Background: The Indigenous population of Australia was estimated as 2.5\% and under-reported. The aim of this study is to improve statistical ascertainment of Aboriginal women giving birth in New South Wales.

Methods: This study was based on linked birth data from the Midwives Data Collection (MDC) and the Registry of Births Deaths and Marriages (RBDM) of New South Wales (NSW). Data linkage was performed by the Centre for Health Record Linkage (CHeReL) for births in NSW for the period January 2001 to December 2005. The accuracy of maternal Aboriginal status in the MDC and RBDM was assessed by consistency, sensitivity and specificity. A new statistical variable, ASV, or Aboriginal Statistical Variable, was constructed based on Indigenous identification in both datasets. The ASV was assessed by comparing numbers and percentages of births to Aboriginal mothers with the estimates by capture-recapture analysis.

Results: Maternal Aboriginal status was under-ascertained in both the MDC and RBDM. The ASV significantly increased ascertainment of Aboriginal women giving birth and decreased the number of missing cases. The proportion of births to Aboriginal mothers in the non-registered birth group was significantly higher than in the registered group.
\end{abstract}

Conclusions: Linking birth data collections is a feasible method to improve the statistical ascertainment of Aboriginal women giving birth in NSW. This has ramifications for the ascertainment of babies of Aboriginal mothers and the targeting of appropriate services in pregnancy and early childhood.

Keywords: Birth, Aboriginality, data, Australia

\section{Background}

The Indigenous population of Australia was estimated as $2.5 \%(517,200)$ of the Australian population as of 30 June 2006 [1,2]. New South Wales (NSW) had the largest proportion of the Indigenous estimated resident population (29-30\%) in Australia [1-3]. An estimated 95\% of the NSW Indigenous population were of Aboriginal origin, 3\% were of Torres Strait Islander origin and the remaining 2\% were of both Aboriginal and Torres Strait Islander origin [1].

In a report by the Australian Institute of Health and Welfare (AIHW), 35,264 women who identified as being of Indigenous origin gave birth to 35,682 babies (3.6\% of all babies) between 2001 and 2004 [4]. The report is

\footnotetext{
* Correspondence: I.pulver@unsw.edu.au

${ }^{3}$ Muru Marri Indigenous Health Unit, School of Public Health \& Community

Medicine, University of New South Wales, NSW 2052, Australia

Full list of author information is available at the end of the article
}

based on data from the National Perinatal Data Collection (NPDC) which is derived from an extract of the Midwives Data Collections (MDC) in each state and territory in Australia [4].

However, it was found that maternal Indigenous status was under-reported in the New South Wales (NSW) MDC and the Registry of Birth Deaths and Marriages (RBDM) birth [5-9]. In the annual NSW Mothers and Babies published by the AIHW, about only $65.5-69.3 \%$ of Indigenous mothers were identified as Indigenous status in the MDC from 2002 to 2005 [5,10,11]. The Australian Bureau of Statistics (ABS) estimated that only $89.3 \%$ of Indigenous mothers were identified as Indigenous in the NSW RBDM from 2002 to 2006 [8].

To adjust for under-enumeration, capture-recapture methods were used to estimate the number of Indigenous mothers and babies [6,7]. The capture-recapture method was derived from techniques used in wildlife

\section{Biomed Central}


science to estimate the size of animal populations. The method was applied to epidemiology and became a useful tool to reduce under-estimation of cases or study population [12]. It was used to estimate the population with hidden natures such as alcohol-related problems, mental illness, human immunodeficiency virus infections and diabetes [13-16]. It also was used to evaluate completeness of cancer surveillance and cerebral palsy registry $[17,18]$.

However, the summary numbers calculated by the capture-recapture method were not on an individual level and could not be used for some data analyses such as multivariate regression analysis. An improved statistical variable of Aboriginality is needed to more accurately reflect the Aboriginal population in NSW.

The under-identification of Indigenous patients was also apparent in other states and territories in Australia [19]. A report by AIHW based on hospital separation data from Queensland, South Australia, Western Australia and the Northern Territory showed that only $89 \%$ of Indigenous patients were identified in public hospital admission records in 2007-08 [19]. An ABS Census showed that the Indigenous population at the time of the 2006 Census was 454,799, while the Census Post Enumeration Survey (PES) estimate was 513,977 people. The difference of 59,178 represents $11.5 \%$ of the PES estimate. However, the net undercount rate for the total population was only $2.7 \%$ [1].

The aim of this study is to improve the statistical ascertainment of Aboriginal women giving birth in New South Wales. The method can be a reference for improving the data quality of Indigenous populations in other states and territories in Australia. It can also be used for quality improvement of other variables which are available in different data collections by data linkage.

\section{Methods}

\section{Data sources}

This study is based on linked population data of births (MDC-RBDM) from January 2001 to December 2005 in New South Wales. The MDC was recorded by midwives and other health care professionals. The scope of the MDC was all live and stillbirths of at least 400 grams birthweight or at least 20 weeks gestation in NSW. Comparatively, the RBDM was recorded by the parents of the child and lodged with the Registrar of Births Deaths and Marriages. It covered all births registered in New South Wales and included information on demographic factors and some pregnancy outcomes.

The Indigenous status in the MDC only includes that relating to the mother. The Indigenous status in the RBDM birth includes that of both the mother and the father.
The values of maternal Indigenous status in both birth data collections include: (1) Aboriginal, (2) Torres Strait Islander, (3) both Aboriginal and Torres Strait Islander and (4) neither Aboriginal nor Torres Strait Islander.

There are few births in NSW reported by Torres Strait Islander mothers, so the combined value of Indigenous status was used in the study.

\section{Data linkage}

Centre for Health Record Linkage (CHeReL) performed the data linkage using probabilistic record linkage methods and choiceMaker software. At the completion of the process, each record in the Master Linkage Key was assigned a record identification number and a Master Linkage Key person ID (Person Project Number (PPN)) to allow linked records for the same individual to be identified and extracted. Checked by 1,000 person IDs selected at random, the false positive rate of the linkage was $0.3 \%$ and false negative $<0.1 \%$.

\section{Definition of Indigenous status}

Indigenous status refers to Aboriginal and Torres Strait Islander origin. Maternal Indigenous status refers to women who have given birth and identify themselves to be of Aboriginal and Torres Strait Islander origin [5].

\section{Assessment of the accuracy of Indigenous status in mothers who reported to be Indigenous}

The accuracy of maternal Indigenous status in the MDC and RBDM birth can be assessed for consistency, sensitivity and specificity. For the purposes of this study, the sensitivity and specificity are based on the assumption that the Indigenous status reported in the MDC and RBDM are correct. So the Indigenous status in the MDC can work as the 'standard' for the calculation of the sensitivity and specificity in the RBDM birth and vice versa. Because the sensitivity and specificity are calculated based on assumptions rather than 'gold standard', the sensitivity in this paper is a 'relative sensitivity' and the specificity is a 'relative specificity'.

The formulas for calculating consistency, sensitivity and specificity are as below. Table 1 illustrates the letters in the formulas.

Table 1 The illustration for calculating consistency, sensitivity and specificity

\begin{tabular}{lllll}
\hline \multicolumn{5}{c}{ RBDM } \\
\hline \multirow{2}{*}{ MDC } & Values & Indigenous & Non-Indigenous & Total \\
\cline { 2 - 5 } & Indigenous & $\mathrm{A}$ & $\mathrm{B}$ & $\mathrm{A}+\mathrm{B}$ \\
\cline { 2 - 5 } & Non-Indigenous & $\mathrm{C}$ & $\mathrm{D}$ & $\mathrm{C}+\mathrm{D}$ \\
\cline { 2 - 5 } & Total & $\mathrm{A}+\mathrm{C}$ & $\mathrm{B}+\mathrm{D}$ & $\mathrm{T}$ \\
\hline
\end{tabular}


Consistency refers to the probability of the same identification of maternal Aboriginality between MDC and RBDM in the Indigenous population (Consistency (\%) = $\left.(A+D) / T^{*} 100\right)$. Sensitivity refers to the probability that maternal Aboriginality is identified in Indigenous population (true positive). Sensitivity of $\mathrm{MDC}(\%)$ is $\mathrm{A} /(\mathrm{A}+\mathrm{C})$ "100; sensitivity of RBDM (\%) is $A /(A+B) * 100$. Specificity refers to the probability that maternal non-Aboriginality is identified in the non-Indigenous population. Specificity of MDC (\%) is $\mathrm{D} /(\mathrm{B}+\mathrm{D}) * 100$, and specificity of RBDM (\%) is $D /(C+D) * 100$. Completeness refers to the extent to which individual variables have non-missing records.

\section{The statistical Aboriginal variable (ASV)}

An improved variable, ASV was created by linking the MDC and RBDM birth. The ASV is based on the following assumptions:

1. Mothers self-reported as Indigenous in either the MDC or RBDM are recorded as Indigenous in ASV.

2. Mothers self-reported as non-Indigenous in both the MDC and RBDM are recorded as non-Indigenous. 3. Mothers self-reported as non-Indigenous in the MDC are recorded as non-Indigenous when the value in the RBDM birth is not stated, and vice versa.

4. Mothers, where the Indigenous status is not stated in the MDC or the RBDM, are classified as missing.

The ASV is an aggregate variable transformed through the linkage of the MDC and RBDM.

\section{The assessment of ASV}

Using capture-recapture analysis, an estimate of the population prevalence of births with Aboriginal and/or Torres Strait Islander mothers can be calculated. The conditions for using the capture-recapture method are met in this study $[7,20]$. The ASV can be assessed by comparing the numbers and percentages of births to Aboriginal mothers with the estimates by capture-recapture analysis. The population of births with Aboriginal mothers $(\mathrm{N})$ can be calculated by the formula below $[16,20,21]$ :

$$
\mathrm{N}=\frac{\left(n_{1}+1\right)\left(n_{2}+1\right)}{\left(n_{12}+1\right)}-1
$$

Where $\mathrm{n}_{1}$ is the number of births to Aboriginal mothers identified by the MDC; $\mathrm{n}_{2}$ is the number of births to Aboriginal mothers identified by the RBDM birth; and $\mathrm{n}_{12}$ is the number of births to Aboriginal mothers identified by both the MDC and RBDM birth.

Approximate unbiased estimate of the variance of $\mathrm{N}$ $[16,20,21]$ :

$$
\operatorname{Var}(\mathrm{N})=\left[\left(\mathrm{n}_{1}+1\right)\left(\mathrm{n}_{2}+1\right)\left(\mathrm{n}_{1}-\mathrm{n}_{12}\right)\left(\mathrm{n}_{2}-\mathrm{n}_{12}\right)\right] /\left[\left(\mathrm{n}_{12}+1\right)^{2}\left(\mathrm{n}_{12}+2\right)\right]
$$

The $95 \%$ confidence intervals $(95 \% \mathrm{CI})$ of $\mathrm{N}$ are:

$$
95 \% \mathrm{CI}=\mathrm{N} \pm 1.96 * \sqrt{\operatorname{Var}(\mathrm{N})}
$$

The estimates of Aboriginal mothers by capture-recapture are assumed to represent the true number or rate of Aboriginal mothers. The maternal Indigenous status was under-reported in the MDC and RBDM and the numbers of Aboriginal mothers were significantly below the estimates calculated by the capture-recapture method. If the ASV can improve the under-reported numbers, it should be higher than the reported number on the MDC and RBDM birth and closer to the estimates by capture-recapture analysis; the closer, the better. If there is no significant difference between the results of the ASV and the estimates from capturerecapture analysis, the ASV is considered to be improved to an optimal level and can represent the true number of Aboriginal mothers.

The chi-square test and 95\% confidence interval were used to assess the differences between the percentages analysed by the ASV and the estimates calculated by the capture-recapture method.

\section{Ethics}

The linkage study was approved by the Aboriginal Health and Medical Research Council, NSW Population \& Health Services Research Ethics Committee and the Human Research Ethics Committees of The University of Sydney and the University of New South Wales. Identifying information such as name, address, date of birth and gender obtained from the MDC baby and RBDM birth datasets was included in the Master Linkage Key which was constructed by the (CHeReL).

\section{Results}

There were a total of 440,994 birth records from the MDC and RBDM between January 2001 and December 2005 in NSW. There were 434,467 birth records in the MDC and 404,734 birth records in the RBDM birth. Theoretically, all births in the NSW MDC can be linked with those from the NSW RBDM birth. However, some birth records cannot be linked. There were 398,207 records which could be linked between the MDC and RBDM births with a linkage rate of $91.65 \%$ in the MDC and $98.39 \%$ in the RBDM birth.

There were some babies who had more than one record in the data collections, so the duplicate records of 677 (one in the linked database, 45 in the non-linked MDC and 631 in the non-linked RBDM) were excluded from the analysis. Eleven records did not state maternal 
Indigenous status in either the MDC or the RBDM birth and were excluded from the analysis.

Table 2 is based on linked records of the MDC and RBDM between 2001 and 2005. It shows the consistency of maternal Indigenous status between the MDC and RBDM, and sensitivity and specificity of maternal Indigenous status in the MDC and RBDM.

The mother's Indigenous statuses were highly consistent between the MDC and RBDM. However, the relative sensitivities in both MDC and RBDM were low in both the MDC and RBDM birth, and the sensitivities in the MDC were lower than the RBDM birth. At least one-third of Indigenous mothers were not identified in the MDC and one-seventh in the RBDM birth.

Table 3 is based on linked records of the MDC and RBDM birth. Estimates were computed using the capturerecapture method. For the linked births, the percentage of maternal Indigenous status was lower in the MDC (1.82\%) than in the RBDM (2.31\%) birth. This compares to the percentages of maternal Indigenous status from the ASV (2.57\%) which were significantly higher than the MDC and RBDM birth alone. Compared with the estimates by the capture-recapture method (2.68\%), the percentages of maternal Indigenous status from the ASV were very close to the estimates and were not significantly different to the estimates each year $(p>0.05)$. However, the overall percentage of maternal Indigenous status from the ASV was lower than the estimate by the capture-recapture method.

Table 4 is based on linked and unlinked birth records. The ASV of maternal Indigenous statuses in the MDC (ASV in MDC) includes the values from the ASV in linked records and unlinked MDC records. Similarly, the maternal Indigenous statuses in RBDM birth (ASV in RBDM birth) include the values from ASV in linked records and unlinked RBDM records. The estimates by the capture-recapture method are based on all records in the MDC or RBDM birth.

The percentages of maternal Indigenous status from the ASV in the MDC and the ASV in the RBDM birth were significantly higher than the original maternal Indigenous statuses in the MDC and RBDM birth respectively. The ASV in the MDC and RBDM birth also reduced the number of missing cases significantly $(\mathrm{p}<$ 0.05 ), especially for the ASV RBDM birth (except for 2005). The improvement in the MDC was more than the RBDM birth. However, the percentages of maternal Indigenous status from the ASV in the MDC and the ASV in the RBDM birth were still significantly lower than the estimates by the capture-recapture method.

Table 5 is based on all birth records including linked records (MDC-RBDM birth), not linked records in the MDC (MDC records only) and not linked records in the RBDM birth (RBDM birth records only). There were more births to Aboriginal women in the non-registered group than the registered group (about five times). However, the maternal Indigenous statuses were not significantly different in the linked registered group and the non-linked registered group.

\section{Discussion}

The Aboriginal status of women giving birth in NSW was under-reported in both the MDC and RBDM birth [5-9]. Table 3 shows the results of linked births, the births which had been registered. Table 4 shows the results of all births recorded in the MDC and RBDM. The absolute number of Aboriginal mothers identified in the MDC was less than the RBDM birth in linked data (Table 3) but more than the RBDM birth when unlinked births in the MDC and RBDM birth (Table 4) were included respectively. In the births that were registered, the babies born to Indigenous mothers in the $\operatorname{MDC}(7,236)$ were less than those in the RBDM birth $(9,003)$ (Table 3$)$. The sensitivity of the MDC (66.7\%) was lower than that of the RBDM birth (86.2\%). But if non-registered births were included in the MDC, the number of babies born to Indigenous mothers in the MDC $(11,349)$ was more than in the RBDM birth $(9,181)$ (Table 4$)$ because Indigenous births are less likely to be registered. Though the data

Table 2 Accuracy of maternal Indigenous status in the MDC and RBDM birth 2001-2005, NSW

\begin{tabular}{|c|c|c|c|c|c|c|c|}
\hline \multirow{2}{*}{ Year } & \multirow[b]{2}{*}{$\mathrm{n}$} & \multicolumn{2}{|c|}{ Consistency } & \multicolumn{2}{|c|}{ MDC } & \multicolumn{2}{|c|}{ RBDM birth } \\
\hline & & $\mathrm{n}_{1}$ & $\%$ & Sensitivity & Specificity & Sensitivity & Specificity \\
\hline 2001 & 80,027 & 79,191 & 98.96 & 65.47 & 99.77 & 87.20 & 99.17 \\
\hline 2002 & 78,338 & 77,495 & 98.92 & 65.30 & 99.74 & 85.90 & 99.16 \\
\hline 2003 & 77,756 & 76,966 & 98.98 & 66.69 & 99.75 & 86.59 & 99.21 \\
\hline 2004 & 79,389 & 78,555 & 98.95 & 67.15 & 99.72 & 85.32 & 99.21 \\
\hline 2005 & 74,631 & 73,974 & 99.12 & 69.33 & 99.76 & 85.88 & 99.35 \\
\hline Total & 390,141 & 386,181 & 98.98 & 66.70 & 99.75 & 86.18 & 99.22 \\
\hline
\end{tabular}

Missing records total 8,066 , accounting for $2.0 \%$.

$\mathrm{n}$ : number of linked records between MDC and RBDM

$\mathrm{n}_{1}$ : consistent number between MDC and RBDM 
Table 3 Maternal Indigenous status in linked birth data (MDC and RBDM birth), 2001-2005, NSW

\begin{tabular}{|c|c|c|c|c|c|c|c|c|c|}
\hline \multirow{3}{*}{$\frac{\text { Sources }}{M D C}$} & \multirow{3}{*}{$\begin{array}{l}\text { Year } \\
2001\end{array}$} & \multicolumn{5}{|c|}{ Maternal Indigenous status } & \multicolumn{3}{|c|}{ Missing } \\
\hline & & \multirow{2}{*}{$\frac{\mathbf{n 1}}{80,931}$} & \multirow{2}{*}{$\begin{array}{c}\text { Indigenous } \\
1,489\end{array}$} & \multirow{2}{*}{$\frac{\%}{1.84}$} & \multicolumn{2}{|c|}{$95 \% \mathrm{Cl}$} & \multirow{2}{*}{$\frac{\text { n2 }}{80,972}$} & \multirow{2}{*}{$\begin{array}{c}\text { Missing records } \\
41\end{array}$} & \multirow{2}{*}{$\begin{array}{c}\% \\
0.05\end{array}$} \\
\hline & & & & & 1.75 & 1.93 & & & \\
\hline & 2002 & 81,303 & 1,497 & 1.84 & 1.75 & 1.93 & 81,348 & 45 & 0.06 \\
\hline & 2003 & 81,131 & 1,472 & 1.81 & 1.72 & 1.90 & 8,1167 & 36 & 0.04 \\
\hline & 2004 & 79,972 & 1,517 & 1.90 & 1.81 & 1.99 & 80,003 & 31 & 0.04 \\
\hline & 2005 & 74,631 & 1,261 & 1.69 & 1.60 & 1.78 & 74,717 & 86 & 0.12 \\
\hline & Total & 397,968 & 7,236 & 1.82 & 1.78 & 1.86 & 398,207 & 239 & 0.06 \\
\hline \multirow[t]{6}{*}{ RBDM birth } & 2001 & 80,068 & 1,894 & 2.37 & 2.26 & 2.48 & 80,972 & 904 & 1.12 \\
\hline & 2002 & 78,378 & 1,858 & 2.37 & 2.26 & 2.48 & 81,348 & 2,970 & 3.65 \\
\hline & 2003 & 77,786 & 1,810 & 2.33 & 2.22 & 2.44 & 81,167 & 3,381 & 4.17 \\
\hline & 2004 & 79,420 & 1,879 & 2.37 & 2.26 & 2.48 & 80,003 & 583 & 0.73 \\
\hline & 2005 & 74,717 & 1,562 & 2.09 & 1.99 & 2.19 & 74,717 & 0 & 0.00 \\
\hline & Total & 390,369 & 9,003 & 2.31 & 2.26 & 2.36 & 398,207 & 7,838 & 1.97 \\
\hline \multirow[t]{6}{*}{ ASV } & 2001 & 80,972 & 2,143 & 2.65 & 2.54 & 2.76 & 80,972 & 0 & 0.00 \\
\hline & 2002 & 81,343 & 2,143 & 2.63 & 2.52 & 2.74 & 81,348 & 5 & 0.01 \\
\hline & 2003 & 81,161 & 2,075 & 2.56 & 2.45 & 2.67 & 81,167 & 6 & 0.01 \\
\hline & 2004 & 80,003 & 2,135 & 2.67 & 2.56 & 2.78 & 80,003 & 0 & 0.00 \\
\hline & 2005 & 74,717 & 1,740 & 2.33 & 2.22 & 2.44 & 74,717 & 0 & 0.00 \\
\hline & Total & 398,196 & 10,236 & 2.57 & 2.52 & 2.62 & 398,207 & 11 & 0.00 \\
\hline \multirow[t]{6}{*}{ Estimates by capture-recapture method } & 2001 & 80,027 & 2,172 & 2.71 & 2.68 & 2.75 & 80,972 & 945 & 1.17 \\
\hline & 2002 & 78,338 & 2,161 & 2.76 & 2.72 & 2.79 & 81,348 & 3,010 & 3.70 \\
\hline & 2003 & 77,756 & 2,090 & 2.69 & 2.66 & 2.72 & 81,167 & 3,411 & 4.20 \\
\hline & 2004 & 79,389 & 2,201 & 2.77 & 2.74 & 2.81 & 80,003 & 614 & 0.77 \\
\hline & 2005 & 74,631 & 1,819 & 2.44 & 2.41 & 2.47 & 74,717 & 86 & 0.12 \\
\hline & Total & 390,141 & 10,443 & 2.68 & 2.64 & 2.71 & 398,207 & 8,066 & 2.03 \\
\hline
\end{tabular}

$\mathrm{n} 1$ Records without 'missing' in Indigenous status

n2 Total linked records

quality of Aboriginality in the RBDM was better than the MDC, many births of Indigenous mothers were not registered. Increasing the rate of birth registrations will be an effective way to improve the data quality of Indigenous status.

However, the under-ascertainment of maternal Aboriginal status can be improved significantly by creating the ASV through linkage of the MDC and RBDM birth. The ASV maximises ascertainment through accepting as valid Indigenous identification in both datasets. The linkage minimises missing values in both the MDC and RBDM birth. The ASV is more accurate and complete and is more suitable for use in advanced computation such as regression analysis.

The ASV improves the data quality at an individual record level rather than providing an estimation of the total number calculated by the capture-recapture method. As a result the ASV can be used for more analyses which are based on individual records. For example, the variable is not only used to describe the rate and distribution of the Indigenous population but can also be used as a independent factor to show the association with other dependent factors such as low birthweight or stillbirth. However, the estimation by the capture-recapture method is an overall number which cannot be used for factor analysis.

Interestingly, although the ASV improves ascertainment of Aboriginal women giving birth, it still under-enumerates estimates derived using a capture-recapture methodology. The impact of this limitation could be minimised by internal data linkage such as linking all of a mother's births to check the Indigenous identification. For example, if a mother had more than one birth, the missing or incorrect values of Aboriginality can be supplemented or confirmed with multiple birth records for that mother. But internal data linkage ideally involves a longer study period given that a mother may have more than one birth. The five-year study period was not long enough for internal linkage. This limitation may also be addressed through additional linkages of other data sources such as Medicare data collection, Admitted Patients Data Collection (APDC), the Emergency Department Data Collection (EDDC) or Register of Congenital Conditions (RCC). It is therefore possible to further improve the ascertainment of Aboriginality to an optimal level by linking the birth data with additional data collections of information on Aboriginality. 
Table 4 Improvement of maternal Indigenous status in MDC and RBDM birth respectively, 2001-2005, NSW

\begin{tabular}{|c|c|c|c|c|c|c|c|c|c|}
\hline \multirow{3}{*}{$\frac{\text { Sources }}{\text { MDC }}$} & \multirow{3}{*}{$\begin{array}{l}\text { Year } \\
2001\end{array}$} & \multicolumn{5}{|c|}{ Maternal Indigenous status } & \multicolumn{3}{|c|}{ Missing } \\
\hline & & \multirow{2}{*}{$\frac{\mathbf{n 1}}{85,809}$} & \multirow{2}{*}{$\begin{array}{c}\text { Indigenous } \\
2,138\end{array}$} & \multirow{2}{*}{$\begin{array}{c}\% \\
2.49\end{array}$} & \multicolumn{2}{|c|}{$95 \% \mathrm{Cl}$} & \multirow{2}{*}{$\frac{\mathbf{n 2}}{85,855}$} & \multirow{2}{*}{$\frac{\text { Missing records }}{46}$} & \multirow{2}{*}{$\begin{array}{c}\% \\
0.05\end{array}$} \\
\hline & & & & & 2.39 & 2.59 & & & \\
\hline & 2002 & 85,954 & 2,183 & 2.54 & 2.43 & 2.65 & 86,003 & 49 & 0.06 \\
\hline & 2003 & 86,366 & 2,189 & 2.53 & 2.43 & 2.63 & 86,406 & 40 & 0.05 \\
\hline & 2004 & 85,584 & 2,333 & 2.73 & 2.62 & 2.84 & 85,616 & 32 & 0.04 \\
\hline & 2005 & 90,491 & 2,506 & 2.77 & 2.66 & 2.88 & 90,587 & 96 & 0.11 \\
\hline & Total & 434,204 & 11,349 & 2.61 & 2.56 & 2.66 & 434,467 & 263 & 0.06 \\
\hline \multirow[t]{6}{*}{ ASV in MDC } & 2001 & 85,850 & 2,792 & 3.25 & 3.13 & 3.37 & 85,855 & 5 & 0.01 \\
\hline & 2002 & 85,994 & 2,829 & 3.29 & 3.17 & 3.41 & 86,003 & 9 & 0.01 \\
\hline & 2003 & 86,396 & 2,792 & 3.23 & 3.11 & 3.35 & 86,406 & 10 & 0.01 \\
\hline & 2004 & 85,615 & 2,951 & 3.45 & 3.33 & 3.57 & 85,616 & 1 & 0.00 \\
\hline & 2005 & 90,577 & 2,985 & 3.30 & 3.18 & 3.42 & 90,587 & 10 & 0.01 \\
\hline & Total & 434,432 & 14,349 & 3.30 & 3.25 & 3.35 & 434,467 & 35 & 0.01 \\
\hline \multirow[t]{6}{*}{ RBDM birth } & 2001 & 81,630 & 1,944 & 2.38 & 2.28 & 2.48 & 82,559 & 929 & 1.13 \\
\hline & 2002 & 79,871 & 1,896 & 2.37 & 2.26 & 2.48 & 82,910 & 3,039 & 3.67 \\
\hline & 2003 & 79,028 & 1,852 & 2.34 & 2.23 & 2.45 & 82,470 & 3,442 & 4.17 \\
\hline & 2004 & 80,540 & 1,907 & 2.37 & 2.26 & 2.48 & 81,141 & 601 & 0.74 \\
\hline & 2005 & 75,654 & 1,582 & 2.09 & 1.99 & 2.19 & 75,654 & 0 & 0 \\
\hline & Total & 396,723 & 9,181 & 2.31 & 2.26 & 2.36 & 404,734 & 8,011 & 1.98 \\
\hline \multirow[t]{6}{*}{ ASV in RBDM birth } & 2001 & 82,534 & 2,193 & 2.66 & 2.55 & 2.77 & 82,559 & 25 & 0.03 \\
\hline & 2002 & 82,836 & 2,181 & 2.63 & 2.52 & 2.74 & 82,910 & 74 & 0.09 \\
\hline & 2003 & 82,403 & 2,117 & 2.57 & 2.46 & 2.68 & 82,470 & 67 & 0.08 \\
\hline & 2004 & 81,123 & 2,163 & 2.67 & 2.56 & 2.78 & 81,141 & 18 & 0.02 \\
\hline & 2005 & 75,654 & 1,760 & 2.33 & 2.22 & 2.44 & 75,654 & 0 & 0 \\
\hline & Total & 404,550 & 10,414 & 2.57 & 2.52 & 2.62 & 404,734 & 184 & 0.05 \\
\hline \multirow[t]{6}{*}{ Estimates by capture-recapture method } & 2001 & 87,442 & 3,351 & 3.83 & 3.75 & 3.92 & & & \\
\hline & 2002 & 87,565 & 3,415 & 3.90 & 3.81 & 3.99 & & & \\
\hline & 2003 & 87,709 & 3,358 & 3.83 & 3.74 & 3.91 & & & \\
\hline & 2004 & 86,754 & 3,528 & 4.07 & 3.98 & 4.15 & & & \\
\hline & 2005 & 91,524 & 3,660 & 4.00 & 3.90 & 4.10 & & & \\
\hline & Total & 440,994 & 17,312 & 3.93 & 3.84 & 4.01 & & & \\
\hline
\end{tabular}

$\mathrm{n} 1$ Records without 'missing' in Indigenous status

n2 Total birth number

Indigenous population was under-estimated not only in New South Wales but also in other states and territories in Australia [19]. The ASV is an option to improve the quality of Indigenous status. On the other hand, data linkage provides an effective way to create or derive statistical variables besides the ASV. It improves the data quality of other variables such as a mother's country of birth and in broader areas such as the study of substance use in which some diagnoses in the APDC in specific perinatal periods can be confirmed by the Pharmaceutical Drugs of Addiction System (PHDAS).

The percentage of births to Aboriginal mothers in the registered birth group in 2005 was significantly lower than in the preceding four-year period, 2001 to 2004. This is because Aboriginal babies' registrations are more likely to be delayed [8]. For example, the MDC birth records in 2001 can be linked to the RBDM birth from 2001 to 2005, 2002 can be linked to 2002 to 2005, and so on. But the delayed registration records after 2005 were not available for the MDC records in 2005 to link.

The number of births between 2001 and 2005 in the MDC (Table 4) was marginally lower than reported by New South Wales Mothers and Babies [5,22]. This is because 46 duplicate records were excluded from this analysis. The number of births recorded between 2001 and 2005 in the RBDM was significantly lower $(25,254)$ than that reported by the ABS [8]. This is because the year used is year of birth while the year in the ABS report refers to year of registration. Furthermore, the data sources were also different. The data used is from registration and the data for the ABS report is from registration and the Census [8]. 
Table 5 Maternal Aboriginality in registered and non-registered groups, 2001-2005, NSW

\begin{tabular}{|c|c|c|c|c|c|c|}
\hline \multirow{2}{*}{$\frac{\text { Year }}{2001}$} & \multirow{2}{*}{$\begin{array}{c}\text { Birth records } \\
\text { Registered }^{\mathrm{a}}\end{array}$} & \multirow{2}{*}{$\frac{\mathbf{n}}{80,972}$} & \multirow{2}{*}{$\frac{\text { Indigenous number }}{2,143}$} & \multirow{2}{*}{$\begin{array}{c}\% \\
2.65\end{array}$} & \multicolumn{2}{|c|}{$95 \% \mathrm{Cl}$} \\
\hline & & & & & 2.54 & 2.76 \\
\hline & Registered ${ }^{\mathrm{b}}$ & 1,562 & 50 & 3.20 & 2.33 & 4.07 \\
\hline & Non-registered & 4,878 & 649 & 13.3 & 12.35 & 14.25 \\
\hline & Total & 87,412 & 2,842 & 3.25 & 3.13 & 3.37 \\
\hline \multirow[t]{4}{*}{2002} & Registered $^{a}$ & 81,343 & 2,143 & 2.63 & 2.52 & 2.74 \\
\hline & Registered ${ }^{\mathrm{b}}$ & 1,493 & 38 & 2.55 & 1.75 & 3.35 \\
\hline & Non-registered & 4,651 & 686 & 14.75 & 13.73 & 15.77 \\
\hline & Total & 87,487 & 2,867 & 3.28 & 3.16 & 3.4 \\
\hline \multirow[t]{4}{*}{2003} & Registered $^{a}$ & 81,161 & 2,075 & 2.56 & 2.45 & 2.67 \\
\hline & Registered $^{b}$ & 1,242 & 42 & 3.38 & 2.37 & 4.39 \\
\hline & Non-registered & 5,235 & 717 & 13.7 & 12.77 & 14.63 \\
\hline & Total & 87,638 & 2,834 & 3.23 & 3.11 & 3.35 \\
\hline \multirow[t]{4}{*}{2004} & Registered $^{a}$ & 80,003 & 2,135 & 2.67 & 2.56 & 2.78 \\
\hline & Registered $^{\mathrm{b}}$ & 1,120 & 28 & 2.5 & 1.59 & 3.41 \\
\hline & Non-registered & 5,612 & 816 & 14.54 & 13.62 & 15.46 \\
\hline & Total & 86,735 & 2,979 & 3.43 & 3.31 & 3.55 \\
\hline \multirow[t]{4}{*}{2005} & Registered $^{a}$ & 74,717 & 1,740 & 2.33 & 2.22 & 2.44 \\
\hline & Registered ${ }^{b}$ & 937 & 20 & 2.13 & 1.21 & 3.05 \\
\hline & Non-registered & 15,860 & 1,245 & 7.85 & 7.43 & 8.27 \\
\hline & Total & 91,514 & 3,005 & 3.28 & 3.16 & 3.4 \\
\hline \multirow[t]{4}{*}{ Total } & Registered $^{a}$ & 398,196 & 10,236 & 2.57 & 2.52 & 2.62 \\
\hline & Registered $^{\mathrm{b}}$ & 6,354 & 178 & 2.8 & 2.39 & 3.21 \\
\hline & Non-registered & 36,236 & 4,113 & 11.35 & 11.02 & 11.68 \\
\hline & Total & 440,786 & 14,527 & 3.3 & 3.25 & 3.35 \\
\hline
\end{tabular}

Registered ${ }^{\text {a }}$ : Linked birth records of MDC-RBDM.

Registered $^{\mathrm{b}}$ : RBDM birth records which cannot be linked with MDC.

Non-registered: MDC birth records which cannot be linked with RBDM.

The assumptions for using the capture-recapture method are described in Additional file 1[23-25].

All linkage studies have limitations. The sensitivity and specificity were calculated based on the assumption that the Indigenous status of women reported in the MDC and RBDM birth was the true and valid status, rather than a 'gold standard'. A validation study of these data would be needed to test this assumption. This is not possible as de-identified data made available from NSW Health is used. The sensitivity and specificity detail differences in the quality of the MDC and RBDM birth.

\section{Conclusion}

Linkage of the birth data collections is a feasible method to improve the statistical ascertainment of Aboriginal women giving birth in NSW. Linkage results in enhanced ascertainment and the construction of a statistical Aboriginal variable. This can be applied to both of the birth collections and other population data. This has ramifications for the ascertainment of babies of Aboriginal mothers and the targeting of appropriate services in pregnancy care and early childhood. Increasing birth registration rate and additional data linkage may improve the ascertainment further.

\section{Additional material}

Additional file 1: Assumptions for using the capture-recapture method. Five assumptions were considered when using the estimates by the capture-recapture method.

\section{Acknowledgements}

We would like to thank Kim Lim and Lee Taylor of the NSW Department of Health Centre for Epidemiology and Glenda Lawrence of Centre for Health Record Linkage for undertaking the linkage and providing expert technical advice. We acknowledge the families who have contributed their data to this study, and recognise the Elders of land on which we work - past, present and future. The study is funded by Sydney University.

\section{Author details}

'PRERU, University of New South Wales, Randwick, NSW 2031, Australia. ${ }^{2}$ Faculty of Health Sciences, Sydney University, Lidcombe NSW 1825, Australia. ${ }^{3}$ Muru Marri Indigenous Health Unit, School of Public Health \& Community Medicine, University of New South Wales, NSW 2052, Australia.

\section{Authors' contributions}

FX participated in study design, data analysis and paper writing. EAS participated in study design, coordination and paper writing. RCM conceived of the study, designed, coordinated and supervised the study. DAB participated in data analysis. LRJP oversaw the aspects of the analysis and reporting of information relating to Indigenous status. All authors read, revised the manuscript and approved the final version. 


\section{Competing interests}

The authors declare that they have no competing interests.

Received: 15 March 2011 Accepted: 30 January 2012

Published: 30 January 2012

\section{References}

1. ABS (Australian Bureau of Statistics): Population Distribution, Aboriginal and Torres Strait Islander Australians Canberra: ABS; 2006.

2. Australian Institute of Health and Welfare: Indigenous housing needs 2009: a multi-measure needs model Canberra: AlHW; 2009.

3. Trewin D, Madden R: The Health and Welfare of Australia's Aboriginal and Torres Strait Islander Peoples Canberra: ABS and AlHW; 2005, Volume ABS Catalogue No. 4704.0, AlHW Catalogue No. IHW14.

4. Leeds KL, Gourley M, Laws PJ, Zhang J, Al-Yaman F, Sullivan EA: Indigenous mothers and their babies, Australia 2001-2004 Canberra: AlHW; 2007.

5. Centre for Epidemiology and Research: New South Wales Mothers and Babies 2006. NSW Public Health Bull 2009, 20(s-1):1-156.

6. Taylor L, Lim K: Quality of reporting of Aboriginality to the NSW Midwives Data Collection. NSW Public Health Bulletin 2000, 11: 206-210.

7. Taylor LK, Mahoney R: Quality of Reporting of Aboriginality to the NSW Midwives Data Collection. Australasian Epidemiologist 2006, 13(1):15-17.

8. ABS (Australian Bureau of Statistics): In Births. Volume 3301.0. Canberra; 2006.

9. Centre for Epidemiology and Research: New South Wales Mothers and Babies 2005. NSW Public Health Bull 2007, 18(s-1):1-135.

10. Laws PJ, Hilder L: In Australia's mothers and babies 2006. Volume Perinatal statistics series no.22. Sydney: AlHW National Perinatal Statistics Unit; 2008.

11. Laws PJ, Sullivan EA: In Australia's mothers and babies 2002. Volume Perinatal statistics series no.15. Sydney: AlHW National Perinatal Statistics Unit; 2004.

12. Brenner $\mathrm{H}$ : Use and limitations of the capture-recapture method in disease monitoring with two dependent sources. Epidemiology 1995, 6(1):42-48.

13. Ponzio M, Perotti PG, Monti MC, Montomoli C, San Bartolomeo P, lannello G, Mariani S: Prevalence estimates of alcohol related problems in an area of northern Italy using the capture-recapture method. Eur J Public Health 2010, 20(5):576-581.

14. Fisher N, Turner SW, Pugh R, Taylor C: Estimating numbers of homeless and homeless mentally ill people in north east Westminster by using capture-recapture analysis. BMJ 1994, 308(6920):27-30.

15. Lievre L, Deveau C, Gerbe J, Enel P, Tran L, De Castro N, Costagliola D, Meyer L: Yearly number of patients diagnosed with primary HIV-1 infection in France estimated by a capture-recapture approach. AIDS 2006, 20(18):2392-2395.

16. Gill GV, Ismail AA, Beeching NJ: The use of capture-recapture techniques in determining the prevalence of type 2 diabetes. QJM 2001, 94(7):341-346.

17. Peragallo MS, Urbano F, Lista F, Sarnicola G, Vecchione A: Evaluation of cancer surveillance completeness among the Italian army personnel, by capture-recapture methodology. Cancer Epidemiol 2011, 35(2):132-138.

18. Surman G, da Silva AA, Kurinczuk JJ: Cerebral palsy registers and highquality data: an evaluation of completeness of the Child register using capture-recapture techniques. Child Care Health Dev 2011.

19. Australian Institute of Health and Welfare: Indigenous identification in hospital separations data-quality report Health Services Series no. 35. Cat. no. HSE 85 Canberra: AlHW; 2010

20. Corrao G, Bagnardi V, Vittadini G, Favilli S: Capture-recapture methods to size alcohol related problems in a population. J Epidemiol Community Health 2000, 54(8):603-610.

21. McCarty DJ, Tull ES, Moy CS, Kwoh CK, LaPorte RE: Ascertainment corrected rates: applications of capture-recapture methods. Int $\mathrm{J}$ Epidemiol 1993, 22(3):559-565.

22. Centre for Epidemiology and Research: New South Wales Mothers and Babies 2001. NSW Public Health Bull 2002, 13(s-4):1-124.

23. Hook EB, Regal RR: Capture-Recapture Methods in Epidemiology: Methods and Limitations. Epidemiol Rev 1995, 17(2):243-264.

24. Register a Birth http://www.bdm.nsw.gov.au/births/registerABirth.htm.

25. Centre for Epidemiology and Research NSW Department of Health: New South Wales Mothers and Babies 2008. NSW Public Health Bull 2010, 21(s-2):1-116

\section{Pre-publication history}

The pre-publication history for this paper can be accessed here: http://www.biomedcentral.com/1471-2288/12/8/prepub

doi:10.1186/1471-2288-12-8

Cite this article as: Xu et al:: Improvement of maternal Aboriginality in NSW birth data. BMC Medical Research Methodology 2012 12:8.

\section{Submit your next manuscript to BioMed Central and take full advantage of:}

- Convenient online submission

- Thorough peer review

- No space constraints or color figure charges

- Immediate publication on acceptance

- Inclusion in PubMed, CAS, Scopus and Google Scholar

- Research which is freely available for redistribution

Submit your manuscript at www.biomedcentral.com/submit 